\title{
Assessing the statistical consistency of the AMB state estimator in distribution systems
}

Link to publication record in Manchester Research Explorer

\section{Citation for published version (APA):}

Almeida, M. C. D., Schincariol, R., \& Ochoa, L. F. (2015). Assessing the statistical consistency of the AMB state estimator in distribution systems. In IEEE/PES Innovative Smart Grid Technologies ISGT Latin America 2015 (pp. 1-6)

\section{Published in:}

IEEE/PES Innovative Smart Grid Technologies ISGT Latin America 2015

\section{Citing this paper}

Please note that where the full-text provided on Manchester Research Explorer is the Author Accepted Manuscript or Proof version this may differ from the final Published version. If citing, it is advised that you check and use the publisher's definitive version.

\section{General rights}

Copyright and moral rights for the publications made accessible in the Research Explorer are retained by the authors and/or other copyright owners and it is a condition of accessing publications that users recognise and abide by the legal requirements associated with these rights.

\section{Takedown policy}

If you believe that this document breaches copyright please refer to the University of Manchester's Takedown Procedures [http://man.ac.uk/04Y6Bo] or contact uml.scholarlycommunications@manchester.ac.uk providing relevant details, so we can investigate your claim.

\section{OPEN ACCESS}




\section{Assessing the Statistical Consistency of the AMB State Estimator in Distribution Systems}

\author{
Madson C. de Almeida and Rafael Schincariol \\ School of Electrical and Computer Engineering \\ University of Campinas \\ Campinas, Brazil \\ madson@ dsee.fee.unicamp.br
}

\author{
Luis F. Ochoa \\ School of Electrical and Electronic Engineering \\ The University of Manchester \\ Manchester, UK \\ luis_ochoa@ ieee.org
}

\begin{abstract}
In this paper the statistical consistency of the singlephase Admittance Matrix-Based State Estimator (AMB SE) originally proposed for distribution systems is for the first time assessed and compared to that of the widely used Traditional SE (TSE). The AMB SE is an interesting alternative for distribution systems given the use of a constant Gain matrix, thus simplifying its implementation and significantly reducing the computational time. However, it is crucial to statistically assess its consistency so as to ensure estimated values and variances (outputs) are in agreement with the specified measurements and variances (inputs). This is carried out using a Monte Carlo analysis and a generic 16-bus UK distribution system. Despite the conversion from actual to equivalent measurements required by the $\mathrm{AMB} \mathrm{SE}$, as well as the approximations regarding the variances of the equivalent measurements, the results demonstrate that the single-phase AMB SE is as consistent and precise as the TSE.
\end{abstract}

Index Terms - Consistency Analysis, Convergence, Distribution System, State Estimator.

\section{INTRODUCTION}

State Estimators are used in power systems to filter errors of the measurement process providing the most likely state of the network and the corresponding estimated variances [1], [2]. Nowadays, state estimators can be seen as consolidated tools in transmission systems, however, the same level of maturity has not yet been reached in distribution systems. This is mainly due to the traditional passive nature of the latter which in general has resulted in a low level of automation, monitoring and communication. Nonetheless, the transition towards much more observable and controllable distribution systems (as part of the Smart Grid concept) will certainly provide the requirements to consolidate SE in distribution systems, enabling the development of applications such as optimal feeder reconfiguration, Volt/VAR control, fault location, and demand-side management [3],[4].

The particular features of distribution systems pose significant challenges to the adoption of state estimators. In addition to the low level of redundancy on the set of measurements, the typical high $r / x$ ratios, the radial or weakly meshed topology and the unbalanced nature of loads, require the use of a more detailed representation [2], [3]. In this context, particular attention has been given to SEs that result in constant and better conditioned Gain matrices, which also speeds up the estimation process. For instance, in [5] an Admittance Matrix-Based State Estimator (AMB SE) was proposed explicitly for distribution systems considering real and imaginary parts of complex voltages as state variables and adopting the conversion from actual to equivalent measurements. This method was extended in [6] by introducing a fast decoupled formulation. According to [6], the approach results in a constant Gain matrix. However, to reach this advantage, the variances of the equivalent measurements need to be considered constant, which is an approximation [7].

In the absence of bad data (i.e., gross errors in measurements and/or parameters), the estimated variances can be seen as a metric for the quality of the estimated quantities. This is because the smaller the estimated variances, the closer the estimates fit the measured values. This concept was first applied in [8] to assess the statistical consistency of distribution system state estimators and it was concluded that the single-phase Traditional State Estimator (TSE) is consistent. In the TSE the measurements are power flows, power injections and voltage magnitudes, while the sate variables are the magnitudes and angles of the bus voltages. The TSE formulated in [8] adopted the normal equation.

In this work, the statistical consistency of the AMB SE is for the first time assessed and compared to that of the widely used TSE formulated via normal equation. This analysis is carried out using a Monte Carlo approach, considering 2,000 simulations in each assessed scenario. Moreover, convergence problems of the AMB SE associated with the presence of voltage measurements are highlighted. A simple approach is proposed to prevent such problems making the AMB SE much more robust. The studies are carried out using a generic 16-bus UK distribution system.

In the next section the main aspects of the TSE and the AMB SE are presented. In section III the concept of consistency is introduced and discussed. The procedure adopted to assess consistency is also described. The results are presented in section IV and the conclusions are drawn in section V. 


\section{Accepted Paper}

\section{STATE ESTIMATORS FOR DISTRIBUTION SYSTEMS}

In this section, the main aspects of the Traditional State Estimator suitable to transmission and distribution system, and the Admittance Matrix Based State Estimator are presented.

\section{A. Traditional State Estimator}

Given a set of measurements $z$ and the corresponding variances, a SE provides the most likely estimate for state variables $x$. The measured values are related to the state variables through the measurement functions $h(x)$ and measurement errors vector $e$, as in (1).

$$
z=h(x)+e
$$

The typical estimate for $x$ is obtained using the formulation via the normal equation and considering the Weighted Least Squares (WLS) approach [1],[2]. Applying the Gauss-Newton method, the state variables are calculated solving iteratively (2), where $H(x)$ is the Jacobian matrix, $W$ is a diagonal weighting matrix and $H(x)^{\prime} W H(x)$ is the Gain matrix.

$$
\begin{gathered}
\Delta x^{v}=\left[H\left(x^{v}\right)^{T} W H\left(x^{v}\right)\right]^{-1} H\left(x^{v}\right)^{T} W\left[z-h\left(x^{v}\right)\right] \\
x^{v+1}=x^{v}+\Delta x^{v}
\end{gathered}
$$

In the TSE the voltage magnitudes and angles are adopted as state variables, while the available measurements can be the active and reactive powers as well as voltages magnitudes. Therefore, $H(x)$ contains nonlinear equations which result in a nonlinear Gain matrix that needs to be updated and factorized at each iteration $v$.

As a very interesting alternative to the TSE, the AMB SE presents a constant Gain matrix that is factorized just once, hence reducing the computational time. In addition, since the Jacobian matrix contains admittances and unitary values instead of nonlinear equations [5], the AMB SE is easier to implement.

\section{B. Admittance Matrix based State Estimator}

This approach adopts the real and imaginary parts of the complex bus voltages as state variables. The available active and reactive powers as well as voltage magnitudes are converted into equivalent complex currents and voltages. The real and imaginary parts of these equivalent measurements are assumed as available measurements[5], [6] and [7]. Thus, $H(x)$ contains conductances and susceptances as well as unitary values associated to voltage equivalent measurements. Additionally, if the variances of the equivalent measurements are constant, the resulting Gain matrix is also constant [2]

It is worth highlighting that despite the use of a constant Gain matrix, the adoption of the normal equation formulation, the use of the Weighted Least Squares (WLS) approach, and the application of the Gauss-Newton method, the solution process is still iterative (3). This is because the equivalent measurements depend on the state variables and must be updated at each iteration. Nonetheless, given that the Gain matrix is constant, it is factorized just once, thus making the iterations of the AMB SE significantly less expensive in computational terms.

$$
\begin{gathered}
\Delta x^{v}=\left[H^{T} W H\right]^{-1} H^{T} W\left[z\left(x^{v}\right)-h\left(x^{v}\right)\right] \\
x^{v+1}=x^{v}+\Delta x^{v}
\end{gathered}
$$

In order to convert actual available measurements in equivalent complex measurements, it is assumed that power measurements are available in pairs. The active and reactive power injections ( $\left.P_{k}^{\text {meas }}, Q_{k}^{\text {meas }}\right)$ and power flows $\left(P_{k m}^{\text {meas }}, Q_{k m}^{\text {meas }}\right)$ are converted according to (4). Note that the current calculated voltages are required, which means that these equivalent measurements need to be updated at each iteration.

$$
\begin{aligned}
& \vec{I}_{k m}^{e q}=\left(\frac{P_{k m}^{\text {meas }}+j Q_{k m}^{\text {meas }}}{V_{k}^{\text {calc }} \angle \theta_{k}^{\text {cal }}}\right)=I_{k m}^{\text {real }}+j I_{k m}^{\text {imag }} \\
& \vec{I}_{k}^{e q}=\left(\frac{P_{k}^{\text {meas }}+j Q_{k}^{\text {meas }}}{V_{k}^{\text {calc }} \angle \theta_{k}^{\text {cal }}}\right)=I_{k}^{\text {real }}+j I_{k}^{\text {imag }}
\end{aligned}
$$

Equation (5) is used to convert actual voltage magnitude measurements into their equivalent complex forms. Again, these measurements are updated at each iteration.

$$
\begin{aligned}
& \vec{V}_{k}^{e q}=V_{k}^{\text {meas }}\left(\frac{V_{k}^{\text {calc }} \angle \theta_{k}^{\text {cal }}}{V_{k}^{\text {calc }}}\right) \\
& \vec{V}_{k}^{e q}=V_{k}^{\text {meas }} \cos \theta_{k}^{\text {cal }}+j V_{k}^{\text {meas }} \sin \theta_{k}^{\text {cal }}
\end{aligned}
$$

The variances of equivalent measurements are derived from measurement variances. This can be done using the error propagation theory and assuming some approximations [9]. To make these variances constant, the last estimated estate or the state calculated by a power flow can be adopted [5], [6] and [9].

\section{Convergence of the AMB SE}

According to (4), one pair of power measurements (active and reactive powers) is required to obtain one pair of equivalent current measurements, i.e., the real and imaginary parts of the equivalent complex current. However, according to (5), one actual magnitude voltage measurement is converted into a pair of equivalent measurements, i.e., the real and imaginary parts of the equivalent complex voltage. Therefore, the number of equivalent voltage measurements is doubled. As a consequence, the observability of the system and the redundancy of the set of measurements are artificially improved. Indeed, it was found that some convergence problems can be faced by the AMB SE when voltage measurements are located far from the substation and voltage angles deviate from zero. In order to solve these issues, it is proposed to discard the imaginary parts of the complex equivalent voltage measurements given that, in general, they are close to zero. Thus, only the real parts of the complex equivalent voltages are included in the AMB SE.

\section{General Aspects of Distribution Systems}

Due to the lack of monitoring devices in distribution systems, pseudo and virtual injection measurements are required to make a system observable. The pseudo measurements are typically obtained from historical data or it can be obtained from low 


\section{Accepted Paper}

voltage smart meters [10]. The virtual measurements are perfect high quality zero injections obtained from nodes without loads and generators. The inaccuracy inherent to the pseudo measurements is addressed by associating them to higher errors and variances, while the high accuracy of virtual measurements requires adopting very small variances. In order to accomplish these requirements, the specified standard deviations are obtained using (7), where $z_{i}^{\text {true }}$ is the true value of the $i$-th measurement calculated from a power flow run and $\varepsilon \%$ is the percentage error attributed to each type of measurement.

$$
\sigma_{i}=\frac{z_{i}^{\text {true }} \times \varepsilon_{\%}}{3 \times 100}
$$

\section{CONSISTENCY OF STATE ESTIMATORS}

Given the system topology and parameters, a SE requires a set of measurements and its specified variances to provide the estimated state and the variances of the estimated quantities. Assuming the absence of gross errors, the smaller the estimated variances, the closer the estimated variables are to the expected values and, therefore, the more the estimated variables fit the available measurements. In this context, a consistent SE must provide estimated values and variances that are consistent or in agreement with the specified measurements and variances. This concept was first applied in [8] to assess the statistical consistency of distribution system state estimators. It was concluded that the TSE was consistent and suitable for state estimation in balanced medium voltage power systems.

In a consistent $\mathrm{SE}$, if the measurements errors $e$ follow a normal distribution, the consistency index (8) follows a $\chi^{2}$ distribution with $n$ degrees of freedom, where $n$ is the number of state variables [8], [11]. In (8), $\hat{x}$ is the estimated state and $x_{\text {true }}$ is the true state obtained from a power flow run. For a specified confidence level $\alpha$, a consistent SE will have a consistency index between the bounds in (9).

$$
\begin{array}{r}
\epsilon=\left(x_{\text {true }}-\hat{x}\right)^{\prime} H^{\prime} W H\left(x_{\text {true }}-\hat{x}\right) \\
\chi_{n}^{2}\left(\frac{1-\alpha}{2}\right) \text { and } \chi_{n}^{2}\left(\frac{1+\alpha}{2}\right)
\end{array}
$$

In order to carry out an adequate consistency assessment, a Monte Carlo analysis is required. In this case, for a consistent SE, the mean of $\epsilon$ will tend to the number of state variables $n$ [8]

The measurements used in the Monte Carlo simulations are obtained adding errors to the true value of the measurements $z_{i}^{\text {true }}$, according to (9). These errors should follow a normal distribution, therefore, $b_{i}$ is a normally distributed random variable with zero mean and unitary variance. The true values of the measurements are obtained from a power flow run. Fig. 1 illustrates the procedure used for consistency assessment.

$$
z_{i}=z_{i}^{\text {true }}+b_{i} \sigma_{i}
$$

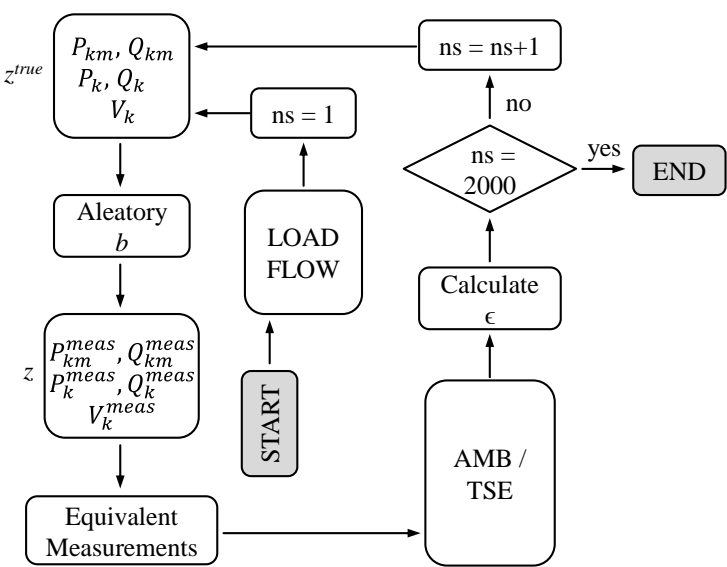

Figure 1 - Monte Carlo Simulation for Consistency Assessment.

\section{CASE STUdy}

\section{E. UKGDS EHV Simplified Network}

The 16-bus UK Generic Distribution System (GDS) EHV Simplified Network presented in Fig. 2 is adopted in the case study [12]. Since this system is fairly balanced, the single-phase $\mathrm{SE}$ will be adopted. Thus, the number of state variables is 31 . The feeders are supplied by $30 \mathrm{MVA} 132 / 33 \mathrm{kV}$ transformers. A voltage regulator is located between buses 8 and 9. The power base is 100MVA.

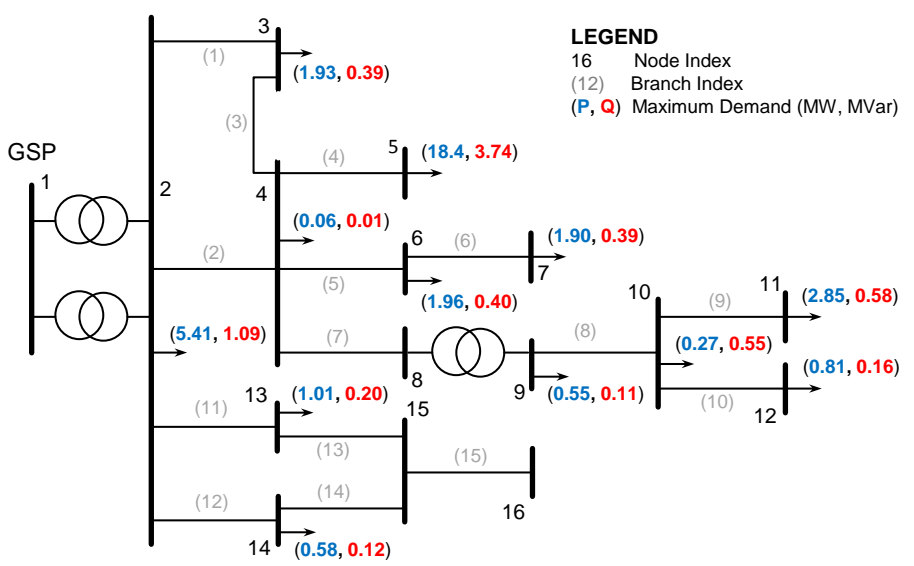

Figure 2 - UKGDS EHV Simplified Network [12].

\section{F. Measurements}

The available measurements are shown in Table I. In case A there are monitors only at the substation and in case B monitors are added to the two biggest loads (buses 5 and 11). The errors for voltages $\varepsilon_{v} \%$ are assumed to be $0.1 \%, 0.5 \%$ or $1 \%$ depending on the assessed scenario. The errors for power flow measurements are 3\% and the errors for pseudo measurements are $30 \%$. The variances for virtual measurements are $10^{-8}$.

TABLE I. METERING PLANS.

\begin{tabular}{|c|c|c|}
\hline Measurements & Case A & Case B \\
\hline Monitors & $\mathrm{V}_{1}, \mathrm{PQ}_{1-2}$ & $\mathrm{~V}_{1}, \mathrm{~V}_{5}, \mathrm{~V}_{11}, \mathrm{PQ}_{1-2}, \mathrm{PQ}_{5-4}, \mathrm{PQ}_{11-10}$ \\
\hline Pseudo & $\mathrm{PQ}_{1}-\mathrm{PQ}_{7}, \mathrm{PQ}_{9}-\mathrm{PQ}_{14}$ & $\mathrm{PQ}_{1}-\mathrm{QP}_{7}, \mathrm{PQ}_{9}-\mathrm{PQ}_{14}$ \\
\hline Virtual & $\mathrm{PQ}_{8}, \mathrm{PQ}_{15}, \mathrm{PQ}_{16}$ & $\mathrm{PQ}_{8}, \mathrm{PQ}_{15}, \mathrm{PQ}_{16}$ \\
\hline
\end{tabular}




\section{Accepted Paper}

\section{G. Convergence Analysis}

Fig. 3 presents the convergence of the AMB for both measurement sets. In case $A$ the convergence is reached with 4 iterations for a tolerance equal to $10^{-5}$. In this case there is only one voltage magnitude measurement that is placed at the substation with an angle equal to zero (reference bus). In case B, if we consider the original AMB SE, i.e., the real and imaginary parts of the equivalent complex voltages, the convergence is not reached even for a smaller tolerance of $10^{-4}$. Consequently, it can be said that, in general, the farther the voltage measurements are from substation, the worse the convergence. However, if we include only the real parts of the equivalent complex voltages, as proposed in this paper, the convergence of the AMB is reached with 4 iterations for a tolerance equal to $10^{-5}$. Even for smaller tolerances the convergence can be reached with a few iterations. This demonstrates the good convergence features of the AMB when adopting the proposed procedure.

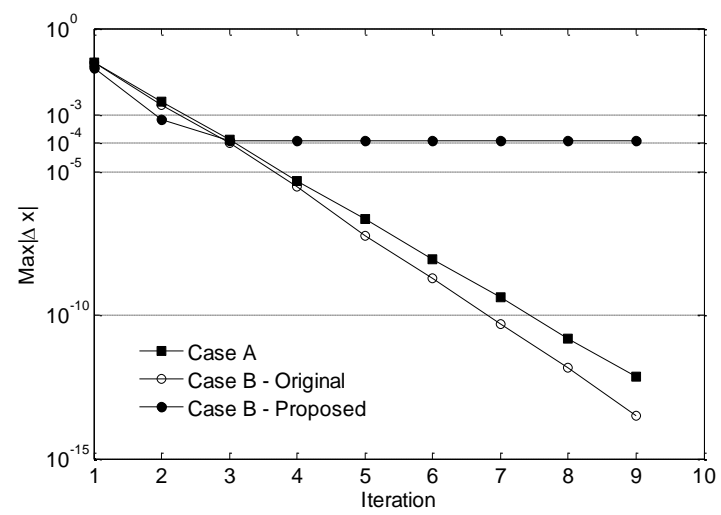

Figure 3 - Convergence of the AMB SE.

\section{H. Consistency Evaluation}

Here a consistency evaluation is carried out considering the proposed procedure for considering equivalent complex voltage measurements. Fig. 4 and Fig 5 present the consistency index $\epsilon$ over the Monte Carlo simulations for the TSE and AMB SE considering the peak load, $\varepsilon_{\nu} \%=0.1 \%$ and the first set of measurements (case A). The bounds calculated for different confidence levels are also shown. It can be seen that in almost all 2,000 simulations the values of $\epsilon$ lie within the specified limits, which indicates that both SE are consistent.

In Tables II, III and IV, the AMB SE and the TSE are compared in terms of consistency and quality of the estimates. Tables II and III refer to the first set of measurements (case A) while Table IV refers to the second set of measurements (case B). It can be seen in all tables that $\epsilon$ tends to the number of state variables, again indicating that both estimators are consistent. In addition, according to the results presented in these tables, the consistency is not significantly affected by the load level, the quality of the voltage monitor placed in substation, or the set of measurements. However, the convergence and the quality of the estimates can change with these aspects. For example, according to Table III, the average value of $\varphi=\left(x_{\text {true }}-\hat{x}\right)^{\prime}\left(x_{\text {true }}-\hat{x}\right)$ increases with the errors of the voltage monitor placed at the substation.
Regarding the quality of the estimates, the results indicate that both estimators present very similar and adequate behaviors. Despite the additional iterations required by the AMB SE in some simulated cases, its constant Gain matrix is factorized only once. This result in a significant reduction in the computational times, particularly for large scale networks.

\section{I. $\quad$ Estimated Voltages and Variances}

Fig. 6 to Fig. 9 present the estimated voltages and the corresponding estimated standard deviation for both estimators considering the peak demand and two different accuracies for the voltage monitors. Fig. 6 and Fig. 7 refers to the first set of measurements (case A) while Fig. 8 and Fig. 9 refers to the second set of measurements (case B). It can be observed that both estimators present very close estimated voltages and standard deviations.

Comparing Fig. 6 to Fig .7 it can be observed that when the accuracy of the voltage meter increases, the estimated variances for voltages decrease. The same can be observed when comparing Fig. 8 and Fig. 9. Additionally, comparing Fig. 6 to Fig. 8 it can be seen that when the number of accurate measurements increases, the estimated variances for voltages decrease. This can also be verified when comparing Fig. 7 to Fig. 9. This behavior is expected for a consistent state estimator.

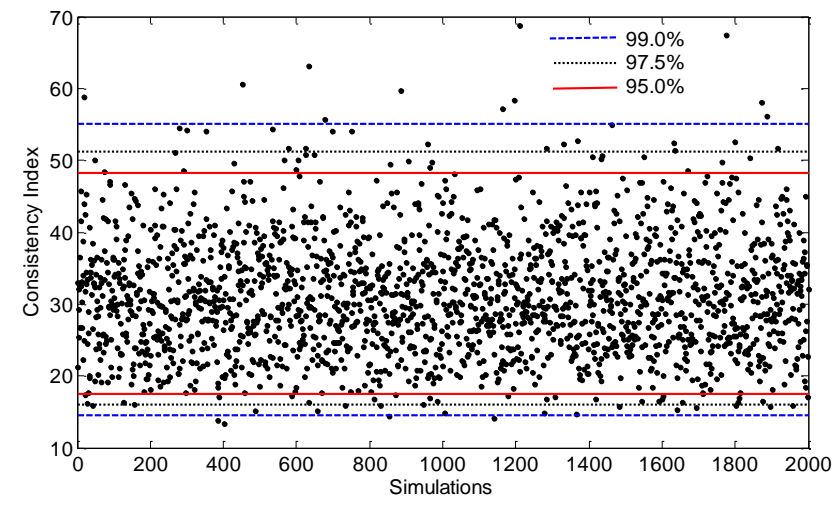

Figure 4 - Consistency of the TSE for the Monte Carlo Simulations.

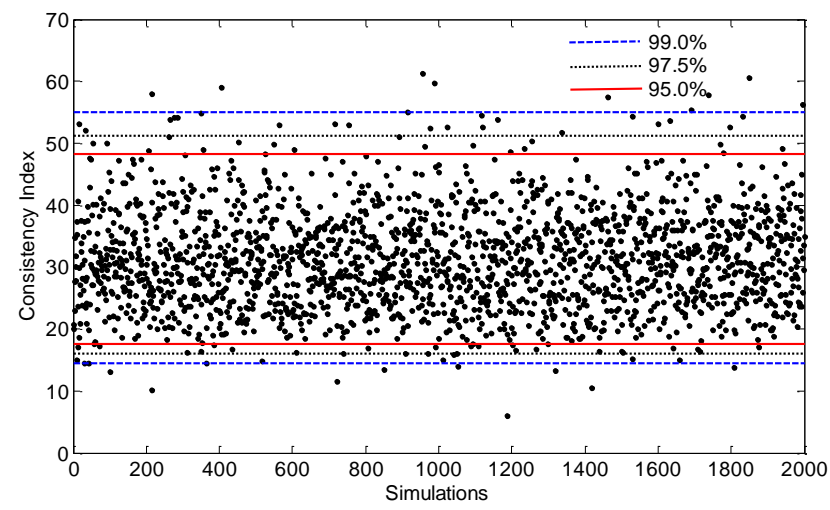

Figure 5-Consistency of the AMB SE for the Monte Carlo Simulations. 
TABLE II. AMB SE X TSE. 2,000 SIMULATIONS PER SCENARIO. 25\%, 50\%, AND $100 \%$ OF THE PEAK LOAD. $\varepsilon_{v}=0.1 \%$ AND METERING CASE A.

\begin{tabular}{|c|ccc|ccc|}
\hline & \multicolumn{3}{|c|}{ AMB } & & TSE \\
& $\mathbf{2 5 \%}$ & $\mathbf{5 0 \%}$ & $\mathbf{1 0 0 \%}$ & $\mathbf{2 5 \%}$ & $\mathbf{5 0 \%}$ & $\mathbf{1 0 0 \%}$ \\
\hline $\begin{array}{c}\text { Simulations out of } \\
\text { bounds for } \alpha= \\
95 \%\end{array}$ & $5.02 \%$ & $5.12 \%$ & $4.98 \%$ & $4.64 \%$ & $4.86 \%$ & $5.38 \%$ \\
\hline $\begin{array}{c}\text { Simulations out of } \\
\text { bounds for } \alpha= \\
\text { 97.5\% }\end{array}$ & $2.55 \%$ & $2.82 \%$ & $2.38 \%$ & $2.60 \%$ & $2.26 \%$ & $2.44 \%$ \\
\hline $\begin{array}{c}\text { Simulations out of } \\
\text { bounds for } \alpha= \\
99 \%\end{array}$ & $1.10 \%$ & $1.18 \%$ & $0.78 \%$ & $1.14 \%$ & $0.96 \%$ & $1.10 \%$ \\
\hline \begin{tabular}{c} 
Average $\epsilon$ \\
\hline $\begin{array}{c}\text { Average number } \\
\text { of iterations }\end{array}$
\end{tabular} & 30.91 & 31.25 & 31.11 & 30.91 & 30.93 & 30.97 \\
\hline Average $\varphi \times 10^{6}$ & 4.07 & 8.87 & 30.10 & 3.97 & 8.82 & 30.84 \\
\hline
\end{tabular}

TABLE III. AMB SE X TSE. 2,000 SIMULATIONS PER SCENARIO. $\varepsilon_{v} \%=1 \%$, $0.5 \%$ AND $0.1 \%$. PEAK LOAD AND METERING CASE A.

\begin{tabular}{|c|ccc|ccc|}
\hline & $\mathbf{3} \%$ & $\begin{array}{c}\text { AMB } \\
\mathbf{0 . 5 \%}\end{array}$ & $\mathbf{0 . 1 \%}$ & $\mathbf{1 \%}$ & $\mathbf{0 . 5 \%}$ & $\mathbf{0 . 1 \%}$ \\
\hline $\begin{array}{c}\text { Simulations out of } \\
\text { bounds for } \alpha= \\
95 \%\end{array}$ & $5.58 \%$ & $5.40 \%$ & $4.98 \%$ & $5.16 \%$ & $5.26 \%$ & $5.38 \%$ \\
\hline $\begin{array}{c}\text { Simulations out of } \\
\text { bounds for } \alpha= \\
97.5 \%\end{array}$ & $2.94 \%$ & $2.54 \%$ & $2.38 \%$ & $2.76 \%$ & $2.94 \%$ & $2.44 \%$ \\
\hline $\begin{array}{c}\text { Simulations out of } \\
\text { bounds for } \alpha= \\
99 \%\end{array}$ & $1.28 \%$ & $1.06 \%$ & $0.78 \%$ & $1.20 \%$ & $1.28 \%$ & $1.10 \%$ \\
\hline \begin{tabular}{c} 
Average $\epsilon$ \\
\hline $\begin{array}{c}\text { Average number } \\
\text { of iterations }\end{array}$
\end{tabular} & 31.61 & 31.19 & 31.11 & 30.79 & 31.12 & 30.97 \\
\hline Average $\varphi$ x $10^{6}$ & 227 & 8 & 4 & 3.5 & 3.2 & 3 \\
\hline
\end{tabular}

TABLE IV. AMB SE X TSE. 2,000 SIMULATIONS PER SCENARIO. 25\% 50\% AND $100 \%$ OF THE PEAK LOAD. $\varepsilon_{v} \%=0.1 \%$ AND METERING CASE B.

\begin{tabular}{|c|c|c|c|c|c|c|}
\hline & \multicolumn{3}{|c|}{ AMB } & \multicolumn{3}{|c|}{ TSE } \\
\hline & $25 \%$ & $50 \%$ & $100 \%$ & $25 \%$ & $50 \%$ & $100 \%$ \\
\hline $\begin{array}{c}\text { Simulations out of } \\
\text { bounds for } \alpha= \\
95 \%\end{array}$ & $4.40 \%$ & $5.04 \%$ & $4.80 \%$ & $4.70 \%$ & $5.14 \%$ & $4.90 \%$ \\
\hline $\begin{array}{c}\text { Simulations out of } \\
\text { bounds for } \alpha= \\
97.5 \%\end{array}$ & $2.94 \%$ & $2.60 \%$ & $2.64 \%$ & $2.46 \%$ & $2.56 \%$ & $2.46 \%$ \\
\hline $\begin{array}{c}\text { Simulations out of } \\
\text { bounds for } \alpha= \\
99 \%\end{array}$ & $0.84 \%$ & $1.00 \%$ & $1.14 \%$ & $0.86 \%$ & $1.02 \%$ & $0.96 \%$ \\
\hline Average $\epsilon$ & 31.11 & 30.83 & 30.88 & 30.80 & 31.17 & 31.05 \\
\hline $\begin{array}{c}\text { Average number } \\
\text { of iterations }\end{array}$ & 4 & 4 & 4 & 3 & 3 & 3 \\
\hline Average $\varphi \times 10^{6}$ & 1.70 & 2.65 & 5.56 & 1.63 & 2.62 & 5.61 \\
\hline
\end{tabular}
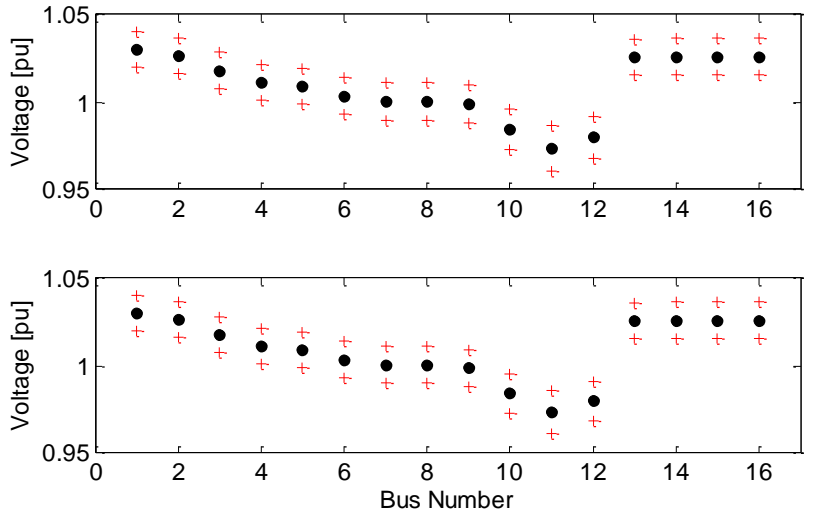

Figure 6 - Estimated voltages $(\bullet) \pm 3 \sigma(+)$ for AMB SE (top) and TSE (bottom). Considering $e_{\nu}=1 \%$. Peak load and metering case A.
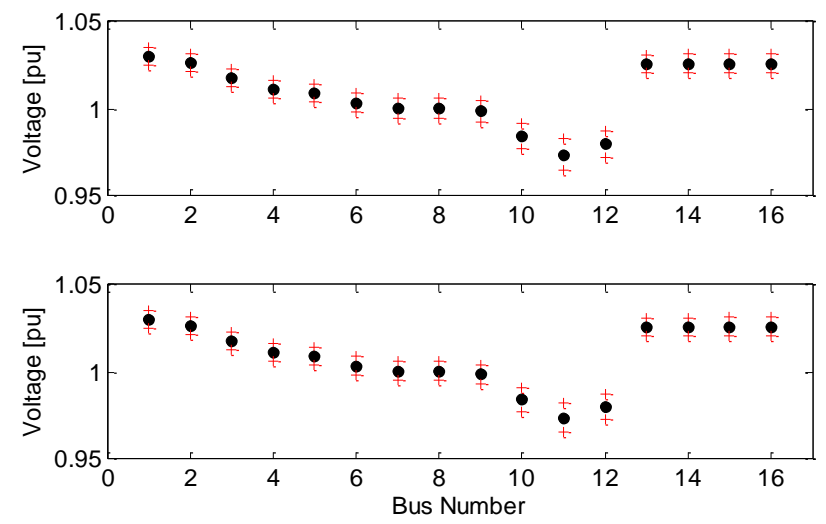

Figure 7 - Estimated voltages $(\bullet) \pm 3 \sigma(+)$ for AMB SE (top) and TSE (bottom). Considering $e_{v \%}=0.5 \%$. Peak load and metering case $\mathrm{A}$.
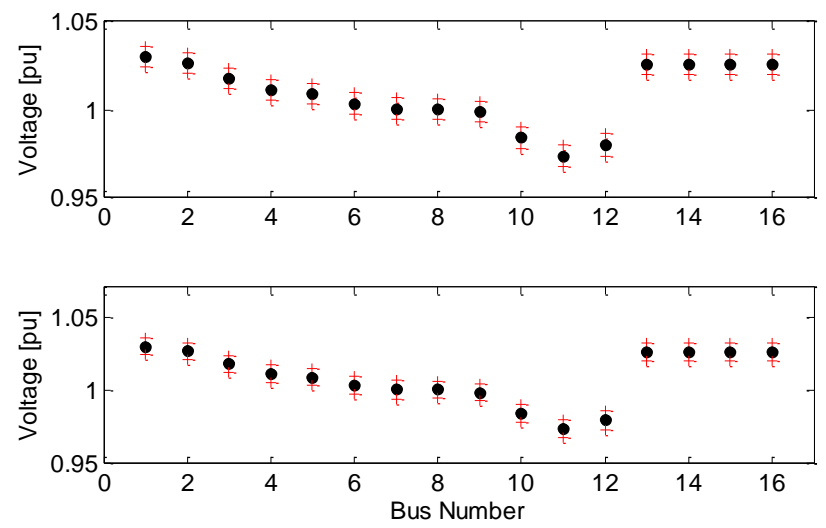

Figure 8 - Estimated voltages $(\bullet) \pm 3 \sigma(+)$ for AMB SE (top) and TSE (bottom). Considering $e_{v}=1 \%$. Peak load and metering case B. 


\section{Accepted Paper}
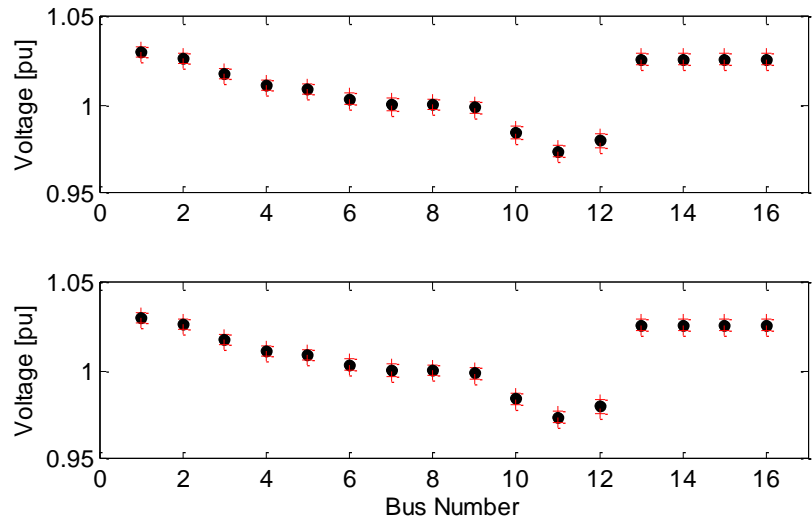

Figure 9 - Estimated voltages $(\bullet) \pm 3 \sigma(+)$ for AMB SE (top) and TSE (bottom). Considering $e_{v} \%=0.5 \%$. Peak load and metering case B.

\section{CONCLUSIONS}

In this paper the consistency of the AMB SE originally proposed for distribution systems was assessed. Some convergence problems of the AMB SE, associated with the presence of voltage magnitude measurements-were highlighted. More importantly, a simple procedure to solve this issue was also proposed.

Despite the conversion from actual to equivalent measurements required by the $\mathrm{AMB} \mathrm{SE}$, as well as the approximations in variances of the equivalent measurements, the results on a generic 16-bus UK distribution system demonstrate that, considering the proposed procedure to incorporate equivalent complex voltages, the single-phase AMB SE is as consistent and precise as the single-phase TSE. As expected for consistent SEs, the average consistency index of both SEs was found to converge to a value close to number of state variables, i.e., 31 .

Based on the above, the AMB SE becomes a viable alternative for state estimation in distribution systems since the use of a constant Gain matrix makes this SE easier to implement and less time consuming than the TSE.

It is important to highlight that the results presented in this paper correspond to the single-phase AMB SE. The three-phase implementation, needed for more detailed analysis of distribution systems, would require some special considerations such as establishing adequate angular references and, therefore, the findings cannot be generalised. Consequently, a similar thorough assessment is required to verify the consistency of the three-phase AMB SE.

\section{REFERENCES}

[1]. A. Monticelli, State Estimation in Electric Power Systems: A Generalized Approach. Kluwer, 1999.

[2]. A. Abur and A. Gómez-Expósito, Power System State Estimation: Theory and Implementation. Marcel Dekker, 2004

[3]. W. H. Kersting, Distribution System Modeling and Analysis. CRC, 2002.

[4]. S. W. Alnaser and L.F. Ochoa, "Advanced Network Management Systems: A Risk-Based AC OPF Approach," Power Systems, IEEE Transactions on, vol.30, no.1, pp.409,418, Jan. 2015.

[5]. C. N. Lu, J. H. Teng, and W. H. E. Liu, "Distribution system state estimation", Power Systems, IEEE Transactions on, vol. 10. no. 1. pp. 229240. Feb. 1995.
[6]. W-M. Lin and J-H. Teng, "Distribution fast decoupled state estimation by measurement pairing", Generation, Transmission and Distribution, IEE Proceedings of, vol. 143. no. 1. pp. 43-48. Jan. 1996.

[7]. W. M. Lin, and J. H. Teng, "State estimation for distribution systems with zero-injection constraints", Power Systems, IEEE Transactions on, vol. 11. no. 1. pp. 518-524. Feb. 1996.

[8]. R. Singh, B. C. Pal and R. A. Jabr, "Choice of estimator for distribution system state estimation", Generation, Transmission \& Distribution, IET, vol.3, no.7, pp.666,678, July 2009.

[9]. D. A. Haughton and G. T. Heydt, "A Linear State Estimation Formulation for Smart Distribution Systems", Power Systems, IEEE Transactions on, vol.28, no.2, pp.1187-1195, May 2013.

[10]. J. Wu, Y. He and N. Jenkins, "A robust state estimator for medium voltage distribution networks," Power Systems, IEEE Transactions on, vol.28, no.2, pp.1008, 1016, May 2013.

[11]. T. W. Anderson, An introduction to multivariate statistical analysis, New York: Willey, 1958.

[12]. Distributed Generation and Sustainable Electrical Energy Centre. UKGDS. Accessed November 2011. 